Article

\title{
Indigenous Probiotic Lactobacillus Isolates Presenting Antibiotic like Activity against Human Pathogenic Bacteria
}

\author{
Debashis Halder ${ }^{1}$, Manisha Mandal ${ }^{2}$, Shiv Sekhar Chatterjee ${ }^{3}$, Nishith Kumar Pal ${ }^{3}$ and \\ Shyamapada Mandal ${ }^{1, *}$ \\ 1 Laboratory of Microbiology and Experimental Medicine, Department of Zoology, University of Gour Banga, \\ Malda 732103, India; debashishalder1991@gmail.com \\ 2 Department of Physiology, MGM Medical College and LSK Hospital, Kishanganj, Bihar 855107, India; \\ debmanisha@rediffmail.com \\ 3 Department of Microbiology, NRS Medical College and Hospital, Kolkata 700014, India; \\ shivshibu@rediffmail.com (S.S.C.); pal_nishith@yahoo.co.in (N.K.P.) \\ * Correspondence: sam.micro11@ugb.ac.in
}

Received: 28 March 2017; Accepted: 9 June 2017; Published: 16 June 2017

\begin{abstract}
Background: Indigenous lactic acid bacteria are well known probiotics having antibacterial activity against potentially pathogenic bacteria. This study aims to characterize the curd lactobacilli for their probiotic potentiality and antagonistic activity against clinical bacteria. Methods: Four curd samples were processed microbiologically for the isolation of lactic acid bacteria (LAB). The LAB strains obtained were identified by conventional methods: cultural aspect, gram-staining, biochemical and sugar fermentation tests. The probiotic properties were justified with tolerance to low-pH, bile salt and sodium chloride, and the antagonistic activity of the lactobacilli against human pathogenic bacteria (Escherichia coli, Proteus vulgaris, Acinetobacter baumannii and Salmonella enterica serovar Typhi) was assessed. Hemolytic activity and antibiotic susceptibility were determined for the lactobacilli isolates, and the cumulative probiotic potential (CPP) values were recorded. Result: Four lactobacilli isolates, L. animalis LMEM6, L. plantarum LMEM7, L. acidophilus LMEM8 and L. rhamnosus LMEM9, procured from the curd samples, survived in low-pH and high bile salt conditions, and showed growth inhibitory activity against the indicator bacteria by agar-well (zone diameter of inhibition; ZDIs: $13.67 \pm 0.58-29.50 \pm 2.10 \mathrm{~mm}$ ) and agar overlay (ZDIs: $11.33 \pm 0.58-35.67 \pm 2.52 \mathrm{~mm}$ ) methods; the average growth inhibitory activity of lactobacilli ranged $233.34 \pm 45.54-280.56 \pm 83.67 \mathrm{AU} / \mathrm{mL}$, against the test bacterial pathogens. All the lactobacilli were non-hemolytic and sensitive to most of the test antibiotics. The CPP values of the isolated LAB were recorded as $80-100 \%$. Conclusion: The curd lactobacilli procured might be used as the valid candidates of probiotics, and bio-therapeutics against bacterial infection to humans.
\end{abstract}

Keywords: lactobacilli; probiotics; antagonistic activity; indicator bacterial pathogens; antibiotic susceptibility; $\gamma$-hemolytic activity; cumulative probiotic potential

\section{Introduction}

Among the lactic acid bacteria (LAB), lactobacilli (the species of the genus Lactobacillus) are the principal members of the intestinal microbiota of vertebrates, including humans, and involve themselves in fermentation of various foods, thereby improving the food quality and safety, and the health and comfort of the consumers as well. Such microorganisms are generally recognized as safe (GRAS) and can be used safely as probiotics [1]. Their adaptation to two different environments, the extra-intestinal environment such as food, and the human intestine (in terms of colonization 
and persistence), exerting varied selective pressure related to their growth rate and carbohydrate metabolism (viz., the food isolates of $L$. reuteri capable of maintaining host-specific physiological characteristics) considered them as probiotics [2-4]. The bacterial (pathogenic) multidrug resistance and formation of biofilm lead to the lack of effectiveness of antibiotics available in the treatment of infection, while the administration of probiotics has been seen functional in preventing and/or counteracting the biofilm-related infection [5]. However, the antibacterial activity of probiotic lactobacilli appears to be strain-specific [6]. Because they act against pathogenic bacteria in the gastrointestinal tract or in the food through multifunctional ways, by secreting antimicrobial substances $\left(\mathrm{H}_{2} \mathrm{O}_{2}\right.$, lactic acid and other organic acids and bacteriocins) [7], competing for nutrients and binding sites, or counteracting the spread within the colonized body [8], probiotic bacteria have the capacity to maintain and influence the composition of the healthy intestinal microbiota [7].

Products containing lactobacilli dominate the global probiotics market; from a wide range of sources, they are used widely in biotechnology and food preservation, and are being explored as therapeutics [9]. It has been demonstrated that the Lactobacillus plantarum isolates could protect the infection caused with Salmonella typhi through interference with growth as well as virulence properties (adherence, invasion, and cytotoxicity) of the pathogen [7]. A large number of lactobacilli isolates, procured from traditional fermented foods prepared with the combination of cereals and dairy materials, including L. acidophilus, L. plantarum and L. rhamnosus had excellent antibacterial activity against Escherichia coli ATCC 700728 standard strain [10]. The lactic acid bacterial strains L. acidophilus, L. plantarum, L. fermentum, L. casei and L. rhamnosus, can effectively be applied against the urinary tract infection causing Proteus species (P. mirabilis and P. vulgaris), as has been reported by Goudarzi et al. [11]. In the earlier study, utilizing some curd lactobacilli and commercially available lactobacilli strains, we demonstrated, singly and in combination, their antibacterial activity against Klebsiella pneumoniae, and E. coli [12].

The current study was undertaken to evaluate the probiotic potentiality and antagonistic effect of four natural lactobacilli strains, procured from various locally available commercial curds and homemade cow milk curds, on gram-negative pathogenic bacteria (Salmonella enterica serovar Typhi, Proteus vulgaris, K. pneumoniae, and E. coli) causing infection to humans.

\section{Materials and Methods}

\subsection{Curd Samples and Lactic Acid Bacteria}

A total of four curd samples, commercial curd 1 (open sample prepared from cow milk), home-made cow milk curd, commercial curd 2 (sachet sample prepared from cow milk) and commercial curd 3 (cup sample prepared from cow milk), were utilized in the current study. In order to isolate the lactic acid bacteria (LAB), de Man, Rogosa and Sharpe (MRS) broth (Hi-Media, Mumbai, India) was inoculated with freshly collected curd samples, and after incubation for $24-48 \mathrm{~h}$ at $35^{\circ} \mathrm{C}$, single discrete colonies were procured on MRS agar (Hi-Media, India) plate, from each of the curd samples, by streak dilution of the broth culture as described earlier [13]. The each of the bacterial colonies isolated was identified performing conventional culture and gram-staining, and physiological and biochemical (catalase, oxidase, indole, nitrate, TSI, MR-VP) tests including sugar fermentation, following Bergey's manual [14], as described earlier [13].

\subsection{Probiotic Property}

The probiotic properties of the isolated lactobacilli were determined through tolerance to sodium chloride, bile salt and low-pH. The bile salt and low-pH (acid) tolerance was tested following the protocol of Liong and Shah [15], and to sodium chloride, by using the protocol of Chowdhury et al. [16], with slight modifications as mentioned elsewhere [13]. Briefly, the isolated lactobacilli were grown (for $24 \mathrm{~h}$ at $37^{\circ} \mathrm{C}$ ), in MRS broth with sodium chloride supplementation of 2, $4 \%$ and $6.5 \%$, and thereafter the growth of lactobacilli, following subculture of the MRS broth cultures, on MRS agar 
(for $24 \mathrm{~h}$ at $37^{\circ} \mathrm{C}$ ), indicated their tolerance to sodium chloride. The tests were conducted under atmospheric carbon dioxide, and were replicated twice.

\subsection{Antagonistic Activity}

The antagonistic activity of four lactobacilli isolates procured (designated as LMEM6, LMEM7, LMEM8 and LMEM9) was determined by agar overlay and agar-well diffusion method, against the indicator strains: Salmonella enterica serovar Typhi (S. typhi from blood culture), Escherichia coli (E. coli from urine culture), Proteus vulgaris (P. vulgaris from pus culture) and Acinetobacter baumannii (A. baumannii from pus culture), procured from different clinical samples, as has been mentioned herein.

\subsubsection{Agar Overlay Method}

The Lactobacillus isolates were spot inoculated, separately, onto the MRS agar plates, using a loop-full ( $\approx 10^{5} \mathrm{CFU} /$ spot) of MRS broth culture (grown at $35^{\circ} \mathrm{C}$ for $48 \mathrm{~h}$ ) of the lactobacilli, and the inoculated plates were incubated at $37^{\circ} \mathrm{C}$ for $48 \mathrm{~h}$. The MRS agar plates containing the growth of lactobacilli in spot form ( $5 \mathrm{~mm}$ diameter) were thereafter overlaid with soft Muller-Hinton agar $(0.8 \%$ agar) pre-mixed with $10^{8} \mathrm{CFU}$ of the indicator stains (one on each MRS agar plate), and incubated, after solidification of the overlaid agar medium, at $37^{\circ} \mathrm{C}$ for $24 \mathrm{~h}$. The zone diameter of inhibition (ZDI) values obtained were measured and interpreted following Shokryazdan et al. [17]: the ZDI >20 mm, 10-20 $\mathrm{mm}$ and $<10 \mathrm{~mm}$ were considered as strong, intermediate and weak inhibitions, respectively. The " $R$ " (width of clear zone) values were also determined as per the formula stated earlier [12]: $R=\frac{(d \text { Inhib }-d \text { Spot })}{2}$ (" $d$ Inhib": the diameter of clear zone around the " $d$ Spot"; and " $d$ Spot": the diameter of spot form of lactobacilli grown on MRS agar plate). The scores of growth inhibition of indicator bacteria were considered as no inhibition capacity when " $R$ " was $<2 \mathrm{~mm}$; low inhibition capacity with " $R$ " values of $2-5 \mathrm{~mm}$, and high inhibition capacity with " $R$ " values $>6 \mathrm{~mm}[18,19]$. All tests were repeated thrice and the data were represented as mean \pm SD (standard deviation).

\subsubsection{Agar-Well Diffusion Method}

The agar-well method was performed according to Tagg and McGiven [20]. On the surface of nutrient agar plate swabbed with indicator bacterial broth culture, wells (of $6 \mathrm{~mm}$ diameter) were prepared, and culture filtrates $(75 \mu \mathrm{L} /$ well) of the isolated lactobacilli were loaded in the wells marked properly with the isolates' names. Following $24 \mathrm{~h}$ incubation at $37^{\circ} \mathrm{C}$ (in presence of atmospheric $\mathrm{CO}_{2}$ ), ZDI (zone diameter of inhibition) values (nearest whole) were recorded, and interpreted as less active, moderately active and highly active with ZDIs $\leq 10 \mathrm{~mm}, 11-14 \mathrm{~mm}$, and $\geq 15 \mathrm{~mm}$, respectively. The tests were performed thrice and the data were represented with mean \pm SD. The antagonistic activity of the test lactobacilli in arbitrary unit per $\mathrm{mL}(\mathrm{AU} / \mathrm{mL})$ was calculated (mean $\pm \mathrm{SD})$ as a measure of production of bioactive components using the formula mentioned elsewhere [21]: $\mathrm{AU} / \mathrm{mL}=\frac{\mathrm{ZDI} \times 1000}{\text { Volume taken in the well }(\mu \mathrm{L})}$, where ZDI denotes "zone diameter of inhibition".

\subsection{Safety Profiling}

The safety profile of the curd isolates of Lactobacillus (LMEM6, LMEM7, LMEM8 and LMEM9) was determined by their hemolytic activity and antibiotic susceptibility.

\subsubsection{Hemolytic Activity}

For hemolytic activity, the overnight grown MRS broth culture of the lactobacilli strains were streaked on blood agar plate (Hi-Media, India) and incubated at $37^{\circ} \mathrm{C}$ for $72 \mathrm{~h}$; thereafter, the plates were observed for the formation of any clean ( $\beta$-hemolysis) or greenish ( $\alpha$-hemolysis) hemolytic zones, or no such zone ( $\gamma$-hemolysis) around the Lactobacillus colonies. 


\subsubsection{Antibiotic Susceptibility}

The antibiotic susceptibility test was performed following disc diffusion method [22], as described before by Halder and Mandal [12], using MRS agar (Hi-Media, Mumbai, India), and approximately $10^{8} \mathrm{CFU}$ inocula from the four lactobacilli strains [23]. The antibiotic discs (Hi-Media, Mumbai, India)

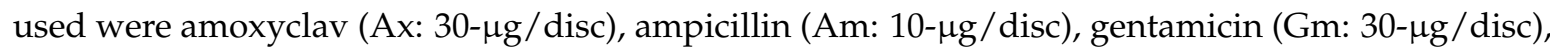
tetracycline (Tc: $30-\mu \mathrm{g} / \mathrm{disc}$ ) and vancomycin (Vm: 30- $\mu \mathrm{g} / \mathrm{disc}$ ). The ZDI values (nearest whole in three consecutive repeats) obtained were interpreted according to the criteria mentioned earlier [24,25]: the lactobacilli were grouped into resistant (ZDI: $\leq 15 \mathrm{~mm}$ ), sensitive (ZDI: $\geq 21 \mathrm{~mm}$ ), or intermediately susceptible (ZDI: 16-20 mm).

\subsection{Cumulative Probiotic Potential}

The probiotic potential of the Lactobacillus isolates was assessed using 5 point scores, and the cumulative probiotic potential (CPP) was calculated as per the formula: CPP $=\frac{\text { Observed score }}{\text { Maximum score }} \times 100$, depicted by Tambekar and Bhutada [26].

\section{Results}

Four lactic acid bacteria, one from each of the four curd samples, were isolated: LMEM6 (from commercial curd 1), LMEM7 (from home-made cow milk curd), LMEM8 (from commercial curd 2) and LMEM9 (from commercial curd 3). All isolates were gram-positive non-spore forming non-motile rod shaped and were negative to catalase and oxidase tests, and thus recognized as Lactobacillus. Following morphological, cultural, biochemical tests and sugar fermentation profile, the isolates were identified as L. animalis LMEM6, L. plantarum LMEM7, L. acidophilus LMEM8 and L. rhamnosus LMEM9. The tolerance test results to different stresses (sodium chloride, low-pH and bile salts) for the isolated lactobacilli are represented in Table 1.

The curd lactobacilli isolates showed excellent antibacterial activity, following agar overlay method, against all indicator bacteria tested (Figure 1). The L. plantarum LMEM7 isolate had top growth inhibitory activity against $A$. baumannii, E. coli and P. vulgaris having ZDIs $32.33 \pm 0.58,30.00 \pm 1.71$ and $35.67 \pm 2.52 \mathrm{~mm}$, respectively, while the $S$. typhi showed highest sensitivity to L. animalis LMEM6 isolate (ZDI: $30.50 \pm 0.71 \mathrm{~mm}$ ); the L. acidophilus LMEM8 isolate had poor activity against all indicator bacterial strains with ZDIs $11.33 \pm 0.58$ to $15.25 \pm 0.96 \mathrm{~mm}$ (Table 2).

Table 1. Physiological stress tolerance test results ( $24 \mathrm{~h}$ incubation) for curd lactobacilli.

\begin{tabular}{ccccccccccc}
\hline Lactobacilli Strains & \multicolumn{3}{c}{$\mathrm{NaCl}(\%)$} & & $\mathrm{pH}$ & & \multicolumn{3}{c}{ Bile Salt (\%) } \\
\hline & $\mathbf{2}$ & $\mathbf{4}$ & $\mathbf{6 . 5}$ & $\mathbf{2}$ & $\mathbf{3}$ & $\mathbf{4}$ & $\mathbf{0 . 1 2 5}$ & $\mathbf{0 . 2 5}$ & $\mathbf{0 . 5}$ \\
\hline L. animalis LMEM6 & + & + & + & + & + & + & + & + & + \\
L. plantarum LMEM7 & + & + & $\mathrm{w}$ & - & $\mathrm{w}$ & + & + & + & - \\
L. acidophilus LMEM8 & + & + & $\mathrm{w}$ & - & $\mathrm{w}$ & + & + & + & $\mathrm{W}$ \\
L. rhamnosus LMEM9 & + & + & + & $\mathrm{w}$ & $\mathrm{w}$ & + & + & + & + \\
\hline
\end{tabular}

Table 2. Antibacterial activity of the isolated lactobacilli, in terms of ZDI, following agar overlay method.

\begin{tabular}{ccccc}
\hline \multirow{2}{*}{ Lactobacillus Isolates } & \multicolumn{4}{c}{ ZDI (mm) \pm SD for Indicator Bacteria } \\
\cline { 2 - 5 } & A. baumannii & E. coli & P. vulgaris & S. typhi \\
\hline L. animalis LMEM6 & $29.67 \pm 0.58$ & $28.25 \pm 0.82$ & $34.50 \pm 0.71$ & $30.50 \pm 0.71$ \\
L. plantarum LMEM7 & $32.33 \pm 0.58$ & $30.00 \pm 1.71$ & $35.67 \pm 2.52$ & $25.25 \pm 1.71$ \\
L. acidophilus LMEM8 & $15.25 \pm 0.96$ & $12.50 \pm 1.29$ & $12.50 \pm 0.71$ & $11.33 \pm 0.58$ \\
L. rhamnosus LMEM9 & $31.33 \pm 1.53$ & $22.67 \pm 1.53$ & $26.00 \pm 2.16$ & $20.67 \pm 1.53$ \\
\hline
\end{tabular}

ZDI: zone diameter of inhibition; SD: standard deviation. 


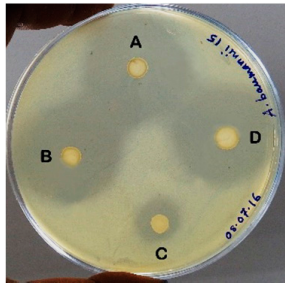

A. baumannii

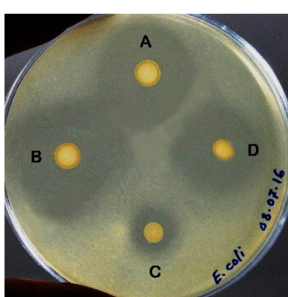

E. coli

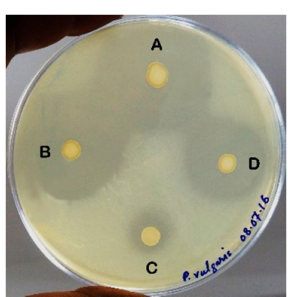

P. vulgaris

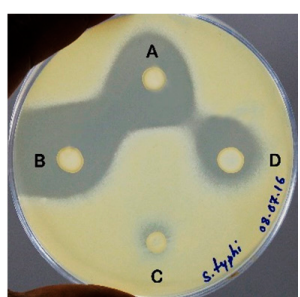

S. typhi

Bacterial Pathogens

Figure 1. Agar overlay technique demonstrates the antibacterial activity of natural lactobacilli isolates against four bacterial pathogens used as the indicator strains. The zones of inhibition have been seen around four test lactobacilli strains (grown on the plates as spot forms) against each of the four bacterial pathogens (A. baumanni, E. coli, P. vulgaris and S. typhi): (A) L. animalis LMEM6; (B) L. plantarum LMEM7; (C) L. acidophilus LMEM8; and (D) L. rhamnosus LMEM9.

The " $R$ " values of the isolated lactobacilli against the gram-negative pathogenic bacteria have been represented in Table 3. The lowest " $R$ " values $(3.17 \pm 0.29-5.13 \pm 0.48 \mathrm{~mm})$ were recorded due to the action of L. acidophilus LMEM8 isolate, while the values, ranging from $10.13 \pm 0.85$ to $15.33 \pm 1.26 \mathrm{~mm}$, were from the action of L. plantarum LMEM7 isolate against the pathogenic bacteria tested; the L. rhamnosus LMEM9 had " $R$ " values $7.83 \pm 0.76-13.17 \pm 0.76 \mathrm{~mm}$, and L. animalis LMEM6 had $14.75 \pm 0.35 \mathrm{~mm}$ against $P$. vulgaris.

The antagonistic activity, following agar-well diffusion (based on the ZDIs values obtained around the culture filtrate-loaded wells on the agar plates), of the lactobacilli isolates against the indicator bacteria is represented in Table 4. The L. animalis LMEM6 had highest activity, with ZDI of $23.67 \pm 1.53 \mathrm{~mm}$, against $P$. vulgaris, while A. baumannii, E. coli and S. typhi were highly sensitive to $L$. rhamnosus LMEM9, having ZDIs $20.33 \pm 1.53,29.50 \pm 2.10$ and $20.00 \pm 1.00 \mathrm{~mm}$, respectively. Among the curd lactobacilli, the L. acidophilus LMEM8 and L. rhamnosus LMEM9 had lowest activity $(182.22 \pm 7.70-191.11 \pm 20.37 \mathrm{AU} / \mathrm{mL})$, among the pathogenic indicator bacterial isolates, while the top level of growth inhibitory components produced was $393.34 \pm 27.76 \mathrm{AU} / \mathrm{mL}$, by L. rhamnosus LMEM9, and the values ranged from $195.56 \pm 7.70$ to $315.55 \pm 20.37 \mathrm{AU} / \mathrm{mL}$, for L. animalis LMEM6, and from $204.45 \pm 20.37$ to $263.34 \pm 25.24 \mathrm{AU} / \mathrm{mL}$, for L. plantarum LMEM7 (Table 5).

Table 3. The " $R$ " values of four natural lactobacilli isolates against the indicator bacterial pathogens: A. baumanni, E. coli, P. vulgaris and S. typhi.

\begin{tabular}{ccccc}
\hline \multirow{2}{*}{ Lactobacillus Isolates } & \multicolumn{3}{c}{$\boldsymbol{R}$ Value $(\mathbf{m m})$, Mean $\pm \mathbf{S D}$, for the Pathogenic Indicator Bacteria } \\
\cline { 2 - 5 } & A. baumannii & E. coli & P. vulgaris & S. typhi \\
\hline L. animalis LMEM6 & $12.3 \pm 0.29$ & $11.50 \pm 0.41$ & $14.75 \pm 0.35$ & $12.75 \pm 0.35$ \\
L. plantarum LMEM7 & $13.67 \pm 0.29$ & $12.63 \pm 0.85$ & $15.33 \pm 1.26$ & $10.13 \pm 0.85$ \\
L.acidophilus LMEM8 & $5.13 \pm 0.48$ & $3.75 \pm 0.65$ & $3.75 \pm 0.35$ & $3.17 \pm 0.29$ \\
L. rhamnosus LMEM9 & $13.17 \pm 0.76$ & $8.83 \pm 0.76$ & $10.50 \pm 1.08$ & $7.83 \pm 0.76$ \\
\hline
\end{tabular}

" $R$ ": zone of clearance; SD: standard deviation.

Table 4. Antibacterial activity of natural lactobacilli isolates against the indicator bacterial pathogens following agar-well diffusion method.

\begin{tabular}{ccccc}
\hline \multirow{2}{*}{ Lactobacillus Isolates } & \multicolumn{3}{c}{ ZDI (mm) \pm SD for Indicator Bacteria } \\
\cline { 2 - 5 } & A. baumannii & E. coli & P. vulgaris & S. typhi \\
\hline L. animalis LMEM6 & $14.67 \pm 0.58$ & $21.67 \pm 1.53$ & $23.67 \pm 1.53$ & $18.33 \pm 1.53$ \\
L. plantarum LMEM7 & $16.00 \pm 2.16$ & $19.75 \pm 1.89$ & $14.67 \pm 1.53$ & $19.50 \pm 1.30$ \\
L. acidophilus LMEM8 & $13.67 \pm 0.58$ & $21.00 \pm 1.00$ & $15.67 \pm 1.53$ & $19.67 \pm 0.58$ \\
L. rhamnosus LMEM9 & $20.33 \pm 1.53$ & $29.50 \pm 2.10$ & $14.33 \pm 1.53$ & $20.00 \pm 1.00$ \\
\hline
\end{tabular}

ZDI: zone diameter of inhibition; SD: standard deviation. 
Table 5. Growth inhibitory activity of lactobacilli expressed in "AU/mL" for bacterial pathogens.

\begin{tabular}{cccccc}
\hline Lactobacillus Isolates & & \multicolumn{2}{c}{ Antagonistic Activity (AU/mL) } & \multicolumn{2}{c}{ Average (AU/mL) } \\
\hline & ST & PV & EC & AB & \\
\hline L. animalis LMEM6 & $244.45 \pm 20.37$ & $315.55 \pm 20.37$ & $288.89 \pm 20.37$ & $195.56 \pm 7.70$ & $261.11 \pm 52.63$ \\
L. plantarum LMEM7 & $260.00 \pm 17.21$ & $204.45 \pm 20.37$ & $263.34 \pm 25.24$ & $213.33 \pm 28.81$ & $235.28 \pm 30.72$ \\
L. acidophilus LMEM8 & $262.22 \pm 7.70$ & $208.90 \pm 20.37$ & $280.00 \pm 13.33$ & $182.22 \pm 7.70$ & $233.34 \pm 45.54$ \\
L. rhamnosus LMEM9 & $266.67 \pm 13.34$ & $191.11 \pm 20.37$ & $393.34 \pm 27.76$ & $271.11 \pm 20.37$ & $280.56 \pm 83.67$ \\
\hline
\end{tabular}

AB: Acinetobacter baumannii; EC: Escherichia coli; PV: Proteus vulgaris; ST: Salmonella enterica serovar Typhi. $\mathrm{AU} / \mathrm{mL}=$ arbitrary unit per $\mathrm{mL}$.

The isolated lactobacilli (L. animalis LMEM6, L. plantarum LMEM7 and L. acidophilus LMEM8 and L. rhamnosus LMEM9) had no clear transparent or greenish zone on the blood agar plates, surrounding their colonies, and thus were found $\gamma$-hemolytic or non-hemolytic. The antibiotic susceptibility test results for the curd lactobacilli are shown in Table 6. All the Lactobacillus isolates had resistance to Vm, and L. animalis LMEM6 had Ax resistance, in addition to the Vm. The all isolated curd lactobacilli showed sensitivity to Tc, while sensitivity to Am and Ax was shown by L. plantarum LMEM7 and L. acidophilus LMEM8; the L. animalis LMEM6 was also sensitive to Am and Gm. The intermediately susceptibility (IS) to Gm was recorded for L. plantarum LMEM7, L. acidophilus LMEM8 and L. rhamnosus LMEM9 isolates, with IS for L. rhamnosus LMEM9 to Am too.

Table 6. Antibiotic susceptibility test results for Lactobacillus isolates from curd samples.

\begin{tabular}{cccc}
\hline Strain & R (ZDI: $\leq \mathbf{1 5} \mathbf{~ m m})$ & IS (ZDI: $\mathbf{1 6 - 2 0 ~} \mathbf{~ m m})$ & S (ZDI: $\geq \mathbf{2 1} \mathbf{~ m m})$ \\
\hline L. animalis LMEM6 & Vm: 6 ; Ax: 15 & - & Am: 22; Tc 19; Gm: 19 \\
L. plantarum LMEM7 & Vm: 6 & Gm: 18 & Ax: 37; Am: 43; Tc: 29 \\
L. acidophilus LMEM8 & Vm: 6 & Gm: 20 & Ax: 27; Am: 31; Tc: 31 \\
L. rhamnosus LMEM9 & Vm: 6 & Am: 20; Gm: 18 & Ax: 23; Tc: 21 \\
\hline
\end{tabular}

Ax: amoxyclav Am: ampicillin; Gm: gentamicin; Tc: tetracycline; Vm: vancomycin; IS: intermediately susceptible; R: resistant; S: sensitive; ZDI: zone diameter of inhibition.

The individual CPP for the Lactobacillus isolates was $80 \%$ for L. animalis LMEM6, and $100 \%$ for the rest three isolates: L. plantarum LMEM7, L. acidophilus LMEM8 and L. rhamnosus LMEM9 (Table 7).

Table 7. Cumulative probiotic potential (CPP) score card for the isolated lactobacilli.

\begin{tabular}{|c|c|c|c|c|c|}
\hline \multirow[t]{2}{*}{ Probiotic Characters } & \multirow[t]{2}{*}{ Indicator Score } & \multicolumn{4}{|c|}{ Individual Probiotic Isolate Score } \\
\hline & & LMEM6 & LMEM7 & LMEM8 & LMEM9 \\
\hline Acidic $\mathrm{pH}$ tolerance & Resistant $=1$ Sensitive $=0$ & 1 & 1 & 1 & 1 \\
\hline Bile salt tolerance & Resistant $=1$ Sensitive $=0$ & 1 & 1 & 1 & 1 \\
\hline $\begin{array}{c}\text { Antagonistic } \\
\text { activity(Average) }\end{array}$ & $\begin{array}{c}\mathrm{AU} / \mathrm{mL} 150-<200=0.5 \\
\mathrm{AU} / \mathrm{mL} \geq 200=1\end{array}$ & 1 & 1 & 1 & 1 \\
\hline ntibiotic sensitivity & $\begin{array}{c}\text { Intrinsic resistance } / \text { Sensitive }=1 \\
\text { Other resistance }=0 \\
\beta \text {-hemolytic }=0\end{array}$ & 0 & 1 & 1 & 1 \\
\hline Hemolytic activity & $\begin{aligned} \alpha \text {-hemolytic } & =0 \\
\gamma \text {-hemolytic } & =1\end{aligned}$ & 1 & 1 & 1 & 1 \\
\hline \multicolumn{2}{|c|}{ CPP for the lactobacilli } & $\begin{array}{c}4 \\
80 \%\end{array}$ & $\begin{array}{c}5 \\
100 \%\end{array}$ & $\begin{array}{c}5 \\
100 \%\end{array}$ & $\begin{array}{c}5 \\
100 \%\end{array}$ \\
\hline
\end{tabular}

\section{Discussion}

Probiotics, which are otherwise called the beneficial gut bacteria, have become a "popular therapy" in recent years, and the researchers are investigating how probiotic microorganisms, viz., Lactobacillus interact with the body [27]. In addition, the isolation and screening of lactobacilli from various locally 
available natural sources is a victorious way to develop new improved probiotic strains with precious medical relevance, though plentiful commercial probiotic strains are currently available in markets worldwide. In the present study four lactobacilli from different curd samples have been procured and their probiotic capacity has scientifically been validated. Samuel et al. [28] isolated a large number of lactic acid bacteria from various food samples (dosa batter, raw milk, curd and paneer), and confirmed their species level identity, based on the cultural, morphological and biochemical characteristics, as L. casei, L. plantarum, L. fermentum, L. brevis, L. acidophilus, L. bulgaricus and L. rhamnosus. Following the criteria mentioned above, the isolated curd lactobacilli in our study have been designated as L. animalis LMEM6, L. plantarum LMEM7, L. acidophilus LMEM8 and L. rhamnosus LMEM9.

It has been demonstrated that for probiotic characterization of lactobacilli, acid tolerance is an important criterion, and the $\mathrm{pH}$ value of 3.0 has been considered standard for such investigation of probiotic strains [29,30]. As per the report of Shokryazdan et al. [17], the entire test Lactobacillus isolates had tolerance to acid at $\mathrm{pH} 3.0$, for $3 \mathrm{~h}$. The L. plantarum strains isolated from fermented olives have been reported to survive for a period of $2-6 \mathrm{~h}$ at $\mathrm{pH} 2.0$ and $\mathrm{pH} 3.0$ [31]. Ehrmann et al. [32] documented that various lactobacilli, including L. animalis, tolerated acidic condition, at $\mathrm{pH} 3.0$, for $4 \mathrm{~h}$; however, the tolerance level varied among the isolates. The Lactobacillus strains retained the viability when exposed them to acidic environment at the $\mathrm{pH}$ values of 2-3 [7]. In earlier studies, as have been conducted by Jose et al. [33] and Liu et al. [34], the lactobacilli tolerated and survived in MRS broth ( $\mathrm{pH}: 3)$, while reduction in viability has been seen at $\mathrm{pH}$. The Lactobacillus strains isolated from river buffalo milk cheese showed survivability in presence of $\mathrm{NaCl}(1-7 \%)$, indicating their high sodium chloride tolerance [35]. The buffalo milk probiotic isolates of L. fermentum and L. acidophilus survived luxuriously in presence of $1-6 \% \mathrm{NaCl}$, whereas moderate growth was seen at $7 \%$ concentration of $\mathrm{NaCl}$ [36]. Regarding bile salt tolerance of probiotic lactobacilli, their survivability in presence of $0.3 \%$ bile salt is physiologically significant, since the bile salts at such a level achieve normally in the human intestine [37], or, differently, the $0.3 \%$ bile salts mimic the physiological bile concentration [38]. As per the investigation of Koll et al. [30], the test strains of Lactobacillus had tolerance to $0.3 \%$ bile. Rahman [36] reported the growth and survivability of L. fermentum and L. acidophilus isolates from buffalo milk at the bile salt concentrations of $0.3-0.5 \%$. It has been reported, similar to our observation, elsewhere that the lactobacilli were seen to grow luxuriously as well as to survive well in $0.3 \%$ of bile salt supplement, whereas poor tolerance was recorded at $0.2 \%$ bile salt condition $[33,39]$. The varied levels of tolerance to $\mathrm{NaCl}$, bile salts and low $\mathrm{pH}(\mathrm{pH}: 2-4)$, have been demonstrated in the four lactobacilli of the current study: L. animalis LMEM6, L. plantarum LMEM7, L. acidophilus LMEM8 and L. rhamnosus LMEM9.

The conception of antagonism of pathogenic bacteria using probiotic lactobacilli has been well documented, and the antibacterial property of such friendly microorganisms has been considered as an important attribute in selecting potential probiotics for the maintenance of healthy microbial balance in the gut. The LAB, mostly the lactobacilli, possessing the capacity to alienate the bacterial pathogens through the production of some antimicrobials, such as $\mathrm{H}_{2} \mathrm{O}_{2}$, organic acids (mainly, lactic acid), bacteriocin, acquires the enviable property for probiotic potentiality and a maintainable substitute to the synthetic antibiotics. The Lactobacillus isolates (L. plantarum, L. fermentum and L. salivarius) from fermented fruits and vegetables had broad antibacterial spectrum (ZDI: 26-28 mm), against food-borne bacterial pathogens, as has been reported by Manzoor et al. [40]. A large number of lactobacilli isolates, including L. acidophilus, L. plantarum and L. rhamnosus, procured from traditional fermented foods prepared with the combination of cereal and dairy materials, had excellent antibacterial activity against E. coli with ZDIs 17-20, 21-30, 14-31 mm, respectively [10].The probiotic Lactobacillus strains: L. fermentum, L. casei and L. acidophilus, isolated from buffalo milk showed growth inhibitory activity against Vibrio cholerae, S. typhi, E. coli, and Shigella species having ZDIs 10-22 mm [36]. The lactobacilli strains, including L. rhamnosus and L. plantarum, procured from dairy food products (commercially available yoghurt and cheese) and rumen contents of cow did not show growth inhibitory activity against E. coli, while Salmonella menston was found sensitive to all the test lactobacilli, as per the 
demonstration of Jose et al. [33]. The supernatant of lactic acid bacteria from the ecological niches of Ecuador, following agar well diffusion, at low $\mathrm{pH}$ conditions ( $\mathrm{pH}$ : 3.0-4.0) had ZDI > $15 \mathrm{~mm}$, against the target bacterial pathogens [41]. Thus, the antagonism of pathogenic bacteria with the lactobacilli is strain/isolate as well as pathogen (target bacteria) specific. The antibacterial antagonism test results, when compared with the two methods (agar overlay and agar-well diffusion) employed in the current study, was in accordance with the results reported by Cadirci and Citak [42], who inspected antagonism of LAB against gram-negative bacteria using the above two methods and found the spot method (agar overlay method) as the effective one in the evaluation of inhibitory activity [42]. However, Rahimifard and Naseri [43] demonstrated well diffusion method as the best to determine antagonism than the other two methods (disk diffusion and spot on lawn) employed, utilizing the probiotic strain, Bifidobacterium bifidum against Salmonella enterica serovar Enteritidis. The lactobacilli from curd samples herein had excellent antibacterial activity in agar-well (ZDI: $13.67 \pm 0.58-29.50 \pm 2.10 \mathrm{~mm}$ ) as well as agar overlay (ZDI: $11.33 \pm 0.58-35.67 \pm 2.52 \mathrm{~mm}$ ) methods, with " $R$ " values $3.17 \pm 0.29-15.33 \pm 1.26 \mathrm{~mm}$. The variation in antibacterial activities as depicted by different authors might be due to the number of CFU of the LAB used (in spot method) and/or the amount of culture supernatant used (in agar well diffusion) as well as the bacteriocin activity $(\mathrm{AU} / \mathrm{mL})$ possessed in it. As has been reported by Iyapparaj et al. [21], the bacteriocin production, in terms of antagonistic activity, for the test lactobacilli ranged 410.4-649.2 AU/mL. The Lactococcus lactic subspecies lactis RM39 showed strong bacteriocin activity (1600 AU/mL) against Klebsiella pneumoniae ATCC 12296, while the other four LAB isolates had inhibitory activity of $800 \mathrm{AU} / \mathrm{mL}$ against $E$. coli [44]. In the current assay, the average growth inhibitory activity of lactobacilli was recorded as $233.34 \pm 45.54-280.56 \pm 83.67 \mathrm{AU} / \mathrm{mL}$, against the test bacterial pathogens.

The probiotic microorganisms must be safe, i.e., the probiotic bacteria like lactobacilli, essentially be incompetent to cause hemolysis as well as gelatin liquefaction in host body. In addition, the probiotic $\mathrm{LAB}$ be sensitive to antibiotics so as to be inept disseminating the resistance property to other pathogenic bacteria in the same niche, or the antibiotic resistance among them should be innate and non-transferable [33]. The hemolysis and gelatin hydrolysis remain the two major virulence factors among pathogenic bacteria, and hence, as the safety aspects that have been evaluated for the curd lactobacilli in the current study, the in vitro test for hemolytic activity has been considered first; the next one in the probiotic safety issues being the antibiotic susceptibility (gelatin hydrolytic activity for the test lactobacilli was not represented herein though all the isolates were negative for the test). In the instant investigation, not a single one of the four Lactobacillus isolates from curd caused $\alpha$-or $\beta$-hemolysis, although $\alpha$-hemolysis among lactobacilli from foods and dairy products is not uncommon [45]. Georgieva et al. [46] reported the sensitivity of natural isolates of lactobacilli (L. acidophilus, L. brevis, L. fermentum and L. plantarum) to Am, Gm, erythromycin (Em) and Tc, and intrinsic resistance to $\mathrm{Vm}$ (non-transferable), and suggested their use as probiotics appropriate in clinical practice. Salminen et al. [47] reported too, the Vm resistance as an intrinsic property of lactobacilli, while the L. plantarum isolates had been reported to be sensitive to most of the antibiotics tested, such as penicillin G, Am, chloramphenicol (Ch) and ciprofloxacin, and Vm [31]. The test lactobacilli including L. fermentum and L. acidophilus were sensitive to Am, Gm, kanamycin (Km), streptomycin $(\mathrm{Sm})$, erythromycin $(\mathrm{Em})$, clindamycin $(\mathrm{Cm}), \mathrm{Tc}$ and $\mathrm{Ch}$ [17]. The antibiotic sensitivity as well as the intrinsic antibiotic resistance property of lactobacilli helps formulate safe probiotic products for human consumption [46]. Many of the Lactobacillus strains are naturally resistant to Vm raising concerns regarding the transferability of such resistance to other pathogenic bacteria, but, being chromosomally encoded the Vm resistance is not readily transferable from lactobacilli, as the fact has been demonstrated through conjugation experiments [48]. The L. kefiri strains though had sensitivity to Tc, clindamycin, Sm, Am, Em, Km, and Gm, the strains CIDCA 8321 and 8345 were resistant to $\mathrm{Ch}$ [18]. The current isolates of curd lactobacilli were sensitive to most of the antibiotics tested with a common resistance to $\mathrm{Vm}$. 
The demonstration of cumulative probiotic potential (CPP) of the native lactobacilli strains has been considered as an improved criterion for the probiotic validation [26,49]. The CPP of L.acidophilus F14, isolated from buttermilk has been recorded as 100\% [50]. Tambekar and Bhutada [26] isolated L. rhamnosus G119b and L. plantarum G95 strains from fermented milk and evaluated probiotic potential with varied CPP values: the value among the isolated Lactobacilli was highest $(100 \%)$ compared to the probiotic preparations (75-85\%) available in the market, and the standard strains of LAB (77-81\%). The CPP for L. brevis UN was reported as $95.83 \%$ [49], while $91.7-100 \%$ among the lactobacilli isolates from fermented foods found in Himachal Pradesh, India [51]. Gautam and Sharma [49] reported L. spicheri $\mathrm{G} 2$ strain, isolated from gundruk, as a potential probiotic fulfilling different probiotic criteria with CPP value $95.83 \%$. In the current study, the curd lactobacilli strains had CPP values $80-100 \%$, and with an average of $95 \%$, and thus the native LAB strains meet the criteria of FAO/WHO [52], in determining the status of a safe probiotic.

\section{Conclusions}

The curd lactobacilli procured might be used as the valid candidates of probiotics, and bio-therapeutics against bacterial infection to humans. To the best of our understanding, this is the first study unfolding the antagonistic activity of four lactobacilli, procured from unexplored native biota of curd, employing two different in vitro methods, against gram-negative pathogenic bacteria, and the probiotic potential of such lactic acid bacteria has been authenticated. However, further studies are required to explore the effectiveness of the antibacterial essence of such native lactobacilli, to be used as the alternative therapeutics, in combating bacterial antibiotic resistance and treating the infection.

Acknowledgments: The corresponding author is grateful to the Department of Science and Technology (Ministry of Science and Technology, Government of India), for funding support of the study (Grant number: SB/EMEQ-025/2013 dated 29-10-2013).

Author Contributions: Debashis Halder performed experimental works; Manisha Mandal designed the study, standardized the protocol and identified bacterial pathogens and lactobacilli, co-wrote the paper; Shiv Sekhar Chatterjee did experimental work for the identification of bacterial pathogens; Nishith Kumar Pal standardized the protocol of the study and identified bacterial pathogens; Shyamapada Mandal designed the study, standardized the protocols, identified lactobacilli, wrote and discussed the entire paper.

Conflicts of Interest: The authors declare no conflict of interest.

\section{References}

1. Fuller, R. Probiotic in man and animals: A review. J. Appl. Bacteriol. 1989, 66, 365-378. [PubMed]

2. Zheng, J.; Zhao, X.; Lin, X.B.; Michael, G.M. Comparative genomics Lactobacillus reuteri from sourdough reveals adaptation of an intestinal symbiont to food fermentations. Sci. Rep. 2015, 5, 18234. [CrossRef] [PubMed]

3. Yang, F.; Hou, C.; Zeng, X.; Qiao, S. The use of lactic acid bacteria as a probiotic in swine diets. Pathogens 2015, 4, 34-45. [CrossRef] [PubMed]

4. Sieladie, D.V.; Zambou, N.F.; Kaktcham, P.M.; Cresci, A.; Fonteh, F. Probiotic properties of lactobacilli strains isolated from raw cow milk in the western highlands of Cameroon. Innov. Romanian Food Biotechnol. 2011, 9 , $12-28$.

5. Vuotto, C.; Longo, F.; Donelli, G. Probiotics to counteract biofilm-associated infections: Promising and conflicting data. Int. J. Oral Sci. 2014, 6, 189-194. [CrossRef] [PubMed]

6. Eid, R.; Jakee, J.E.; Rashidy, A.; Asfour, H.; Omara, S.; Kandil, M.M.; Mahmood, Z.; Hahne, J.; Seida, A.A. Potential antimicrobial activities of probiotic Lactobacillus strains isolated from raw milk. Probiot. Health 2016, $4,138$.

7. Abdel-Daim, A.; Hassouna, N.; Hafez, M.; Ashor, M.S.A.; Aboulwafa, M.M. Antagonistic activity of Lactobacillus isolates against salmonella typhi in vitro. Biomed. Res. Int. 2013, 1-12. [CrossRef] [PubMed]

8. Di Cerbo, A.; Palmieri, B.; Aponte, M.; Morales-Medina, J.C.; Iannitti, T. Mechanisms and therapeutic effectiveness of lactobacilli. J. Clin. Pathol. 2015, 69, 1-17. [CrossRef] [PubMed] 
9. Sun, Z.; Harris, H.M.B.; McCann, A.; Guo, C.; Argimon, S.; Zhang, W.; Yang, X.; Jeffery, I.B.; Cooney, J.C.; Kagawa, T.F.; et al. Expanding the biotechnology potential of lactobacilli through comparative genomics of 213 strains and associated genera. Nat. Commun. 2015, 6, 1-13. [CrossRef] [PubMed]

10. Mashak, K. Antimicrobial activity of lactobacillus isolated from kashk-e zard and tarkhineh, two Iranian traditional fermented foods. Int. J. Enteric Pathog. 2016, 4, e34692. [CrossRef]

11. Goudarzi, L.; Kermanshahi, R.K.; Moosavinezhad, Z. Investigating the effect of probiotic bacteria on urease activity and swarming movement in Proteus species. Curr. Res. Microbiol. Biotechnol. 2016, 4, 827-834.

12. Halder, D.; Mandal, S. Antibacterial potentiality of commercially available probiotic lactobacilli and curd lactobacilli strains, alone and in combination, against human pathogenic bacteria. Transl. Biomed. 2016, 7, 1-7. [CrossRef]

13. Halder, D.; Mandal, S. Curd lactobacilli with probiotic potentiality. Transl. Biomed. 2015, 6, 1-6. [CrossRef]

14. Holt, J.G.; Krieg, N.R. Bergey's Manual of Systematic Bacteriology; Williams and Wilkins: Baltimore, MD, USA, 1984.

15. Liong, M.T.; Shah, N.P. Acid and bile tolerance and cholesterol removal ability of lactobacilli strain. J. Dairy Sci. 2005, 88, 55-66. [CrossRef]

16. Chowdhury, A.; Hossain, M.N.; Mostazir, N.J.; Fakruddin, M.; Billah, M.; Ahmed, M. Screening of Lactobacillus spp. from buffalo yoghurt for probiotic and antibacterial activity. J. Bacteriol. Parasitol. 2012, 3, 156. [CrossRef]

17. Shokryazdan, P.; Sieo, C.C.; Kalavathy, R.; Liang, J.B.; Alitheen, N.B.; Jahromi, M.F.; Ahmed, M. Probiotic potential of Lactobacillus strains with antimicrobial activity against some human pathogenic strains. Biomed. Res. Int. 2014, 2, 1-16. [CrossRef] [PubMed]

18. Carasi, P.; Diaz, M.; Racedo, S.M.; Antoni, G.D.; Urdaci, M.C.; Serradell, M.A. Safety characterization and antimicrobial properties ofkefir-isolated Lactobacillus kefiri. Biomed. Res. Int. 2014, 2, 1-7. [CrossRef] [PubMed]

19. Pisano, M.B.; Viale, S.; Conti, S.; Fadda, M.; Deplano, M.; Melis, M.P.; Deiana, M.; Cosentino, S. Preliminary evaluation of probiotic properties of Lactobacillus strains isolated from Sardinian dairy products. Biomed. Res. Int. 2014, 2, 1-8. [CrossRef] [PubMed]

20. Tagg, J.R.; McGiven, A.R. Assay system for bacteriocins. Appl. Microbiol. 1971, 21, 943-944. [PubMed]

21. Iyapparaj, P.; Maruthiah, T.; Ramasubburayan, R.; Prakash, S.; Kumar, C.; Immanuel, G.; Palavesam, A. Optimization of bacteriocin production by Lactobacillus sp. MSU3IR against shrimp bacterial pathogens. Aquat. Biosyst. 2013, 9, 12. [CrossRef] [PubMed]

22. Bauer, A.J.; Kirby, W.; Turck, M. Antibiotic susceptibility testing by standardized single disc method. Am. J. Clin. Pathol. 1996, 45, 493-496.

23. Saha, A.; Mandal, S. In vitro assessment of two commercial honey samples for antibacterial and antioxidant activities. Austin J. Trop. Med. Hyg. 2015, 1, 1002.

24. Liasi, S.A.; Azmi, T.I.; Hassan, M.D.; Shuhaimi, M.; Rosfarizan, M. Antimicrobial activity and antibiotic sensitivity of three isolates of lactic acid bacteria from fermented fish product Budu. Malays. J. Microbiol. 2009, 5, 33-37.

25. Vlkova, E.; Rada, V.; Popelarova, P.; Trojanová, I.; Killer, J. Antimicrobial susceptibility of bifidobacteria isolated from gastrointestinal tract of calves. Livest. Sci. 2006, 105, 253-259. [CrossRef]

26. Tambekar, D.H.; Bhutada, S.A. An evaluation of probiotic potential of Lactobacillus sp. from milk of domestic animals and commercial available probiotic preparations in prevention of enteric bacterial infections. Recent Res. Sci. Technol. 2010, 2, 82-88.

27. Reardon, S. Microbiome therapy gains market traction. Nature 2014, 509, 269-270. [CrossRef] [PubMed]

28. Samuel, S.S.; Shukla, S.; Ramteke, P.W.; Sushma. Isolation and identification of antagonistic Lactobacillus spp. isolated from dairy products against selected pathogens. J. Pharm. Innovat. 2016, 5, 8-13.

29. Sahadeva, R.P.K.; Leong, S.F.; Chua, K.H. Survival of commercial probiotic strains to pH and bile. Int. Food Res. J. 2011, 18, 1515-1522.

30. Koll, P.; Mandar, R.; Marcotte, H.; Leibur, E.; Mikelsaar, M.; Hammarstrom, L. Characterization of oral lactobacilli as potential probiotics for oral health. Oral Microbiol. Immunol. 2008, 23, 139-147. [CrossRef] [PubMed]

31. Mourad, K.; Nour-Eddine, K. In vitro preselection criteria for probiotic Lactobacillus plantarum strains of fermented olives origin. Int. J. Probiot. Prebiot. 2006, 1, 27-32.

32. Ehrmann, M.A.; Kurzak, P.; Bauer, J.; Vogel, R.F. Characterization of lactobacilli towards their use as probiotic adjuncts in poultry. J. Appl. Microbiol. 2002, 92, 966-975. [CrossRef] [PubMed] 
33. Jose, N.M.; Bunt, C.R.; Hussain, M.A. Comparison of microbiological and probiotic characteristics of lactobacilli isolates from dairy food products and animal rumen contents. Microorganisms 2015, 3, 198-212. [CrossRef] [PubMed]

34. Liu, X.; Liu, W.; Zhang, Q.; Tian, F.; Wang, G.; Zhang, H.; Chen, W. Screening of lactobacilli with antagonistic activity against enteroinvasive Escherichia coli. Food Control 2013, 30, 563-568. [CrossRef]

35. Jeronymo-Ceneviva, A.B. Probiotic properties of lactic acid bacteria isolated from water buffalo mozzarella cheese. Probiot. Antimicrob. Protein 2014, 6, 141-156. [CrossRef] [PubMed]

36. Rahman, S.M.K. Probiotic properties analysis of isolated lactic acid bacteria from buffalo milk. Arch. Clin. Microbiol. 2015, 7, 1.

37. Sjovall, P. On the concentration of bile acids in the human intestine during absorption, bile acids and sterioids 74. Acta Physiol. Scand. 1959, 46, 339-345. [CrossRef] [PubMed]

38. Maragkoudakis, P.A.; Zoumpopouloua, G.; Miarisa, C.; Kalantzopoulosa, G.; Potb, B. Probiotic potential of Lactobacillus strains isolated from dairy products. Int. Dairy J. 2006, 16, 189-199. [CrossRef]

39. Hoque, M.Z.; Akter, F.; Hossain, K.M.; Rahman, M.S.M.; Billah, M.M.; Islam, K.M.D. Isolation, identification and analysis of probiotic properties of Lactobacillus spp. from selective regional yoghurts. World J. Dairy Food Sci. 2010, 5, 39-46.

40. Manzoor, A.; Ul-Haq, I.; Baig, S.; Qazi, J.I.; Seratlic, S. Efficacy of locally isolated lactic acid bacteria against antibiotic-resistant uropathogens. Jundishapur J. Microbiol. 2016, 9, e18952. [CrossRef] [PubMed]

41. Benavides, A.B.; Ulcuango, M.; Yepez, L.; Tenea, G.N. Assessment of the in vitro bioactive properties of lactic acid bacteria isolated from native ecological niches of Ecuador. Rev. Argent. Microbiol. 2016, 48, $236-244$. [CrossRef] [PubMed]

42. Cadirci, B.H.; Citak, S. A comparison of two methods used for measuring antagonistic activity of lactic acid bacteria. Pak. J. Nutr. 2005, 4, 237-241.

43. Rahimifard, N.; Naseri, M. Evaluation and comparison of three antimicrobial activity methods using Bifidobacteriabifidum and Bifidobacteria infantis as probiotic bacteria against Salmonella enterica serotype Enteritidis. J. Bacteriol. Mycol. 2016, 2, 00024. [CrossRef]

44. Shehata, M.G.; Sohaimy, S.A.E.; El-Sahn, M.A.; Youssef, M.M. Screening of isolated potential probiotic lactic acid bacteria for cholesterol lowering property and bile salt hydrolase activity. Ann. Agric. Sci. 2016, 61, 65-75. [CrossRef]

45. Kaktcham, N.F.; Zambou, F.M.; El-Soda, T.M.; Choudhary, M.I. Antimicrobial and safety properties of lactobacilli isolated from two Cameroonian traditional fermented foods. Sci. Pharm. 2012, 80, 189-203. [CrossRef] [PubMed]

46. Georgieva, R.; Yocheva, L.; Tserovska, L.; Zhelezova, G.; Stefanova, N.; Atanasova, A. Antimicrobial activity and antibiotic susceptibility of Lactobacillus and Bifidobacterium spp. intended for use as starter and probiotic cultures. Biotechnol. Biotechnol. Equip. 2015, 29, 84-91. [CrossRef] [PubMed]

47. Salminen, S.; von Wright, A.; Morelli, L.; Marteau, P.; Brassart, D.; de Vos, W.M. Demonstration of safety of probiotics-A review. Int. J. Food Microbiol. 1998, 44, 93-106. [CrossRef]

48. Tynkkynen, S.; Singh, K.V.; Varmanen, P. Vancomycin resistance factor of Lactobacillus rhamnosus GG in relation to enterococcal vancomycin resistance (van) genes. Int. J. Food Microbiol. 1998, 41, 195-204. [CrossRef]

49. Gautam, N.; Sharma, S. Characterization of bacteriocin producer Lactobacillus brevis as potential probiotic strain. J. Microbiol. Biotechnol. Food Sci. 2015, 5, 216-220. [CrossRef]

50. Handa, S.; Sharma, N. Evaluation of health benefits of lassi (Buttermilk): A traditional non alcoholic beverage of northern India. J. Innov. Biol. 2016, 3, 297-301.

51. Sharma, N.; Gupta, A.; Handa, S. An exploration of rich microbial diversity of rare traditional functional foods of Trans Himalayan state of India with proven additional probiotic effect. Int. J. Curr. Microbiol. Appl. Sci. 2014, 3, 999-1014.

52. FAO and WHO. Guidelines for the Evaluation of Probiotics in Food: Report of a Joint FAO/WHO Working Group on Drafting Guidelines for the Evaluation of Probiotics in Food; Food and Agriculture Organization; World Health Organization: London, ON, Canada, 2002.

(C) 2017 by the authors. Licensee MDPI, Basel, Switzerland. This article is an open access article distributed under the terms and conditions of the Creative Commons Attribution (CC BY) license (http:/ / creativecommons.org/licenses/by/4.0/). 